\title{
Umbilical cord blood procalcitonin and $C$ reactive protein concentrations as markers for early diagnosis of very early onset neonatal infection
}

\author{
N Joram, C Boscher, S Denizot, V Loubersac, N Winer, J C Roze, C Gras-Le Guen
}

Arch Dis Child Fetal Neonatal Ed 2006;91:F65-F66. doi: 10.1136/adc.2005.074245

Procalcitonin (PCT) and $\mathrm{C}$ reactive protein (CRP) concentrations in umbilical cord blood of 197 neonates were measured to evaluate their value as markers of infection. Sixteen of the neonates were infected. The sensitivity, specificity, and negative and positive predictive values were respectively $87.5 \%, 98.7 \%, 87.5 \%$, and $98.7 \%$ for PCT and $50 \%, 97 \%$, $67 \%$, and $94 \%$ for CRP. Serum PCT in cord blood seems to be a useful and early marker of antenatal infection.

$M$ aternofetal bacterial infection is one of the most common causes of neonatal morbidity and mortality. Early diagnosis and treatment are vital to improve outcome. In the absence of reliable infection markers during the first hours of life, paediatricians often start early antibiotic treatment in newborn infants with risk factors for infection, exposing a considerable number of patients to unnecessary treatment. Procalcitonin (PCT) has been implicated as a sensitive and specific marker of bacterial infection. $^{12}$ However, it is well established that PCT concentrations in the neonate show a physiological increase during the first two days of life, which complicates the interpretation of results during this period. ${ }^{3}$ The aim of this study was to evaluate the diagnostic value of PCT measured in umbilical cord blood before this physiological increase as an early and specific marker of neonatal bacterial sepsis.

\section{STUDY DESIGN \\ Patients}

We conducted a prospective study from November 2003 to April 2004 in all children born with a suspected maternofetal infection. Three groups were defined according to clinical, biological, and bacterial criteria: infected, colonised, and noninfected non-colonised. Infected neonates had clinical and postnatal biological signs of sepsis, and a positive central (blood or cerebrospinal fluid) or peripheral bacteriological sample. Colonised neonates had a positive gastric sample, without any clinical or biological sign of sepsis. Non-infected non-colonised neonates had no sign of infection and a negative gastric sample. We also studied a group of newborns without any risk factors, which constituted a control group.

\section{Measurements}

We measured PCT concentration in umbilical cord blood samples using an immuno-chromatographic semiquantitative test (PCT-Q; Brahms, Hennigsdorf, Germany) and C reactive protein (CRP) concentration using an immunoreactive quantitative method. We also measured PCT in maternal blood to evaluate its relevance in the diagnosis of chorioamnionitis.
}

\section{Judgment criteria}

The first judgment criterion was the sensitivity, specificity, and positive and negative predictive values, and positive and negative likelihood ratios of PCT, as assessed by a comparison of PCT concentrations in infected neonates with those in the groups of colonised and non-infected non-colonised neonates. The second criterion involved a comparison of PCT and CRP as predictive markers of neonatal infection.

\section{RESULTS}

A total of 197 newborn infants (167 with suspected maternofetal infection and 30 in the control group) were included in the study; 161 were full term and 36 were preterm.

\section{Measurement of PCT and CRP}

Figure 1 shows PCT and CRP concentrations for neonates with suspected maternofetal infection, irrespective of term. From the PCT results, we chose $0.5 \mu \mathrm{g} / \mathrm{l}$ as the cut-off point that offered the best sensitivity without significantly decreasing specificity. For CRP, according to the receiver operating characteristic curve, we chose a cut-off point of $5 \mathrm{mg} / \mathrm{l}$, which is lower than the threshold of $10 \mathrm{mg} / \mathrm{l}$, evident in neonatological literature, for postnatal measurements. ${ }^{4}$ Only two of the 16 infected newborns had a negative PCT concentration, lower than $0.5 \mu \mathrm{g} / \mathrm{l}$, and eight of the 16 had a CRP concentration lower than $5 \mathrm{mg} / \mathrm{l}$. On the other hand, only two non-infected neonates had a PCT concentration higher than $0.5 \mu \mathrm{g} / \mathrm{l}$, four of which had a CRP concentration higher than $5 \mathrm{mg} / \mathrm{l}$. The results were similar in the groups of preterm and full term neonates. Sensitivity, specificity, and positive and negative predictive values were respectively $87.5 \%$ (95\% confidence interval 71 to 100$), 98.7 \%$ (97.7 to 99.7$), 87.5 \%$ (71 to 100 ), and $98.7 \%$ (97.7 to 99.7) for PCT, and 50\% (25 to 75 ), $97 \%$ (94 to 100 ), $67 \%$ (40 to 94 ), and $94 \%$ ( 81 to 100 ) for CRP. The positive and negative likelihood ratios were respectively 67.3 and 0.13 for PCT and 16.7 and 0.51 for CRP. As shown in fig 1 , we also discovered that the PCT concentration allowed discrimination between infection and simple colonisation. Comparing the diagnostic values of the two markers, PCT showed significantly higher sensitivity and negative predictive value than CRP $(\mathrm{p}<0.01)$. We did not find any significant difference with respect to specificity and positive predictive value. The positive and negative likelihood ratios of PCT were more remarkable than those of CRP, as shown in the nomogram of Bayes (fig 2). We found a posttest probability of infection with PCT of $85 \%$ if positive and $1 \%$ if negative. All but one of the PCT measurements in maternal blood was negative.

Abbreviations: $C R P, C$ reactive protein; $P C T$, procalcitonin 


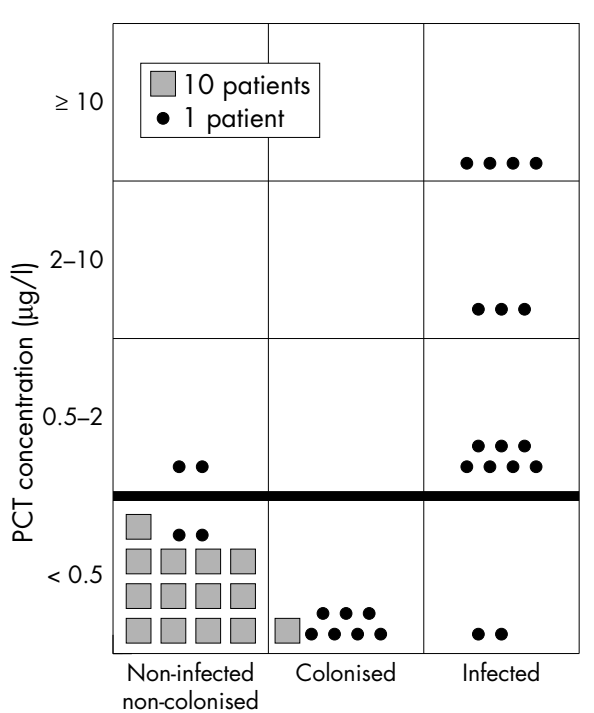

\section{DISCUSSION}

PCT measured in umbilical cord blood appears to be a sensitive and specific marker of antenatal infection, with high positive and negative predictive values. It also presents good positive and negative likelihood ratios, and appears to be more reliable than CRP. Focusing on PCT concentrations in umbilical cord blood before the physiological increase or an eventual respiratory or haemodynamic failure makes interpretation of the diagnostic value of PCT concentration easier. ${ }^{5}$ On the other hand, the limitation of such an early PCT measurement is that it does not allow the detection of "late" maternofetal infection related to perpartum or postnatal contamination.

In clinical practice, PCT measurement in umbilical cord blood should be useful for the early detection of infected

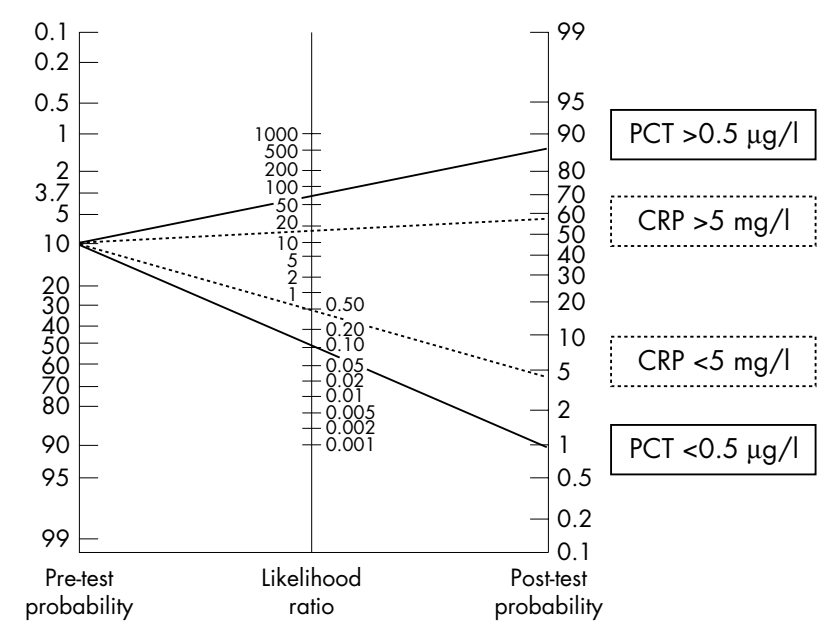

Figure 2 A nomogram of Bayes for applying positive and negative likelihood ratios calculated for selected ranges of values of procalcitonin (PCT) and $C$ reactive protein (CRP). This nomogram compares a pre-test likelihood of being infected with a post-test likelihood. Pre-test probability was 10\%, which corresponds to the incidence of this pathology in the population studied. Thus, by using PCT, the likelihood of being infected increases from $10 \%$ to $85 \%$ when $\mathrm{PCT}$ is positive, and the likelihood of being non-infected decreases from $10 \%$ to $1 \%$ when PCT is below $0.5 \mu \mathrm{g} / \mathrm{l}$. neonates, and its good negative predictive value should result in a reduction in the number of patients treated unnecessarily. In particular, PCT measurement should allow the clinician to distinguish infections from simple colonisations. Interestingly, PCT seems to be present in full term and preterm neonates. This reduction in antibiotic prescriptions would represent a direct advantage for neonates, because of the potential toxicity of antibiotics, and an indirect ecological advantage, by reducing antibiotic selection pressure. Although the specificity and negative predictive value for PCT in this study were correct and precisely evaluated with a confidence interval of $1 \%$, the number of infected patients was too small to provide definitive sensitivity and positive predictive value. Although these rapid tests look promising, our results, obtained in a relatively small number of neonates, should be confirmed by a properly designed trial to confirm that PCT is a useful tool for diagnosing sepsis in newborn infants.

\section{Authors' affiliations}

N Joram, C Boscher, S Denizot, J C Roze, C Gras-Le Guen, Département de Périnatologie, Hôpital Mère Enfant, Nantes, France

V Loubersac, Laboratoire de Biochimie, Nantes

N Winer, Service de Gynécologie Obstétrique, Hôpital Mère Enfant, Nantes

C G-L Guen, Laboratoire d'Antibiologie, Faculté de Médecine, Nantes

Competing interests: none declared

Correspondence to: Dr Gras-le Guen, Département de Périnatologie, Hôpital Mère Enfant, Quai Moncousu, Chu Nantes, Nantes 44000, France; christele.grasleguen@chu-nantes.fr

Accepted 22 July 2005

\section{REFERENCES}

1 Gendrel D, Assicot M, Raymond J, et al. Procalcitonin as a marker for the early diagnosis of neonatal infection. J Pediatr 1996;128:570-3.

2 Chiesa C, Panero A, Rossi NA, et al. Reliability of procalcitonin concentrations for the diagnosis of sepsis in critically ill neonates. Clin Infect Dis 1998;26:664-72

3 Sachse C, Dressler F, Henkel E. Increased serum procalcitonin in newborn infants without infection. Clin Chem 1998;44:1343-4

4 Mathers NJ, Pohlandt F. Diagnostic audit of C-reactive protein in neonatal infection. Eur J Pediatr 1987;146:147-51.

5 Lapillonne A, Basson E, Monneret G, et al. Lack of specificity of procalcitonin for sepsis diagnosis in premature infants. Lancet 1998;351:1211-12. 